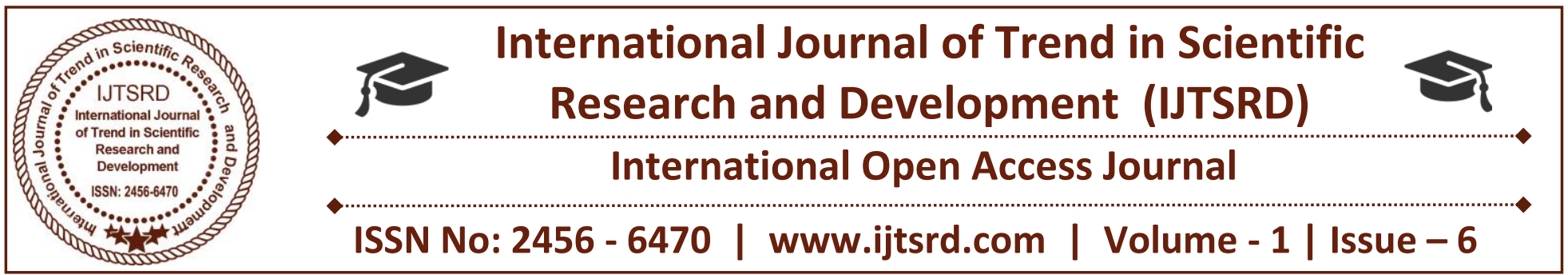

\title{
A Survey on Different Posture Adopted by the Food Production Staff at Work
}

\author{
Ms. Aarti Memkiya \\ Family Resource Management, P.G.Department of \\ Home Science, Sardar Patel University, Vallabh \\ Vidyanagar, Gujarat
}

\author{
Dr. Paulomi Dalal \\ Adhoc, Family Resource Management, P.G. \\ Department of Home Science, Sardar Patel \\ University, Vallabh Vidyanagar, Gujarat, India \\ paulomidalal@gmail.com
}

\begin{abstract}
Background: The health constraint faced by production workers affects the quality of the work. The productivity of the workers is affected by the Work Related Musculoskeletal Disorder (WMSD) which limits the movement of the workers. The comfort workplace condition, known as ergonomic environment is important to prevent the occurrence of the WMSD. Proper ergonomic workplace considers the condition of the workers while doing the assigned work.
\end{abstract}

Objectives: The objectives of this study are 1) to explore the socio-demographic characteristics of food production staff. 2) To find out different postures adopted by the food production staff at work. 3) To find out different body parts involved with musculoskeletal disorders.

Methodology: Total 60 respondents were selected conveniently for this study from the hotels of Vadodara, Anand and Ahmedabad city of Gujarat State. Data was collected by using structured interview schedule.

Results: Most of the education level was Higher Secondary (55\%). The duration of job experience was 4-8 years (52\%). From the findings, the workers were exposed to the awkward posture which leads to the Work Musculoskeletal Disorders (WMSDs). The results show that the workers are exposed to the WMSD in different level of risks. The result indicates that most discomfort of the body regions was in the lower back (23\%), wrist $(21 \%)$ and calf muscle $(26 \%)$. The most common risk factors were working in awkward position, repetitive task and carry heavy load.

Conclusion: Musculoskeletal pain has significant impact on work ability among the food production staff.

Keywords: Hospitality, hotel, WRMDs, food production staff

\section{INTRODUCTION:}

The Indian hospitality industry has emerged as one the key industries driving growth of the services sector in India. Hospitality industry is a part of service industry. A hospitality unit like restaurant, bars, hotels, etc. consists of many sections like cooking, cleaning, managing etc. The term kitchen is derived from the French word "Cuisine" which literally means Art of cooking or food preparation in the kitchen. But in the modern concept of catering the cuisine not only refers to Art of cooking foods in the kitchen, it also indicates the style of service offered to serve the food. Food production or kitchen department is responsible for the actual preparation of food items where as the Food and Beverage $(\mathrm{F} \& \mathrm{~B})$ service department is responsible for systematic service of food from the hot or cold plates of kitchen to the customer's tables as per their choices or order. 
The staff of Food production working in the hotels must withstand the pressure, string of working for long hours, prolong standing posture, lifting heavy pots and kettles and working near hot ovens and grills. There are some major risk factors include repetition, awkward posture, force exertion, static posture, mechanical contact stress, temperature and vibration.

Food production staff may experience fatigue and discomfort when performing highly repetitive tasks, working in repeated and sustained or awkward postures, performing heavy physical work, and using forceful exertion. Continued work under these conditions may result in chronic injuries to muscles, tendons, ligaments, nerves and blood vessels. Injuries of these types are known as Work Related Musculoskeletal Disorders (WRMSDs).

It does occur when the physical capabilities of the worker do not match the physical requirements of the job. Musculoskeletal Disorders can happen to anyone from restaurant workers and industrial employees to athletes, hobbyists, office workers, etc. (Sanon, 2014)

Ergonomics is the study of how to improve the fit between the tasks of the job and the employees who person the work. Thus, this study was aimed to find out the different postures adopted by the food production staff at work and musculoskeletal disorders among them.

Actual and potential losses due to musculoskeletal disorder cause enormous problems globally. This study will be helpful to explore common musculoskeletal complaints among the food production staff in hotel industry. This study will be helpful for the professions or professional physiotherapy and with this connection other hospitality professionals, students will have a chance together their knowledge from this study. Finally, the study will add to existing knowledge about the impact of musculoskeletal disorders on food production staff and can serve as a reference material for further research.

\section{Objectives of the study:}

To explore the socio-demographic characteristics of food production staff of selected hotels.

$>$ To find out different postures adopted by the food production staff at work.

$>$ To find out different body parts involved with musculoskeletal disorders.

\section{Delimitations of the study:}

$>$ Respondent should be working since last two (02) years in the same property.

$>$ The respondent should be present at the time of survey of the present study.

\section{LITERATURE REVIEW:}

1. WRULDs are chronic (persistent) injuries such as tenosynovitis and carpal tunnel syndrome and result from repetitive tasks such as on production lines. WRULDs account for around 23\% of cases of occupational ill health in food production manufacture. Poor working conditions and the absence of an effective work injury prevention program in industrially developing countries has resulted in a very high rate of MSDs (Jafry \& Neill, 2000)

2. Many jobs have risks that can lead to sprains and strains to the back and other parts of the body. Risk factors of WMSDs include workplace activities such as heavy load lifting, repetitive tasks, and awkward working postures, demographic characteristics factors are also known to be important predictive variables. (Linton \& Kamwendo, 1989)

3. Fazi, H., et.al. (2017) identified the current problems related to ergonomic in food production process, to analyze the actual production data by using Rapid Upper Limb Assessment (RULA) and Rapid Entire Body Assessment (REBA) and to recommend the ergonomic workplace environment based on the condition of the study. The study was done at a Small and Medium Enterprises (SME) food production company in the Klang Valley of Malaysia. The condition of the workers affects the productivity of the company due to workers' health deficiency. From the findings, the workers are exposed to the awkward posture which leads to the WorkMusculoskeletal Disorders (WMSDs). The results show that the workers are exposed to the WMSD in different level of risks which causes high absenteeism among the workers.

4. Khare, T., (2014), data showed that occupational risks were noticed among workers which can result in health hazards. Statistical analysis showed the significant difference between physiological cost of work and different activities such as preparation, cooking, serving and 
dishwashing performed by the restaurant workers. It was found that the restaurant workers faced lot of problems due to non availability of relaxing chair at their work unit. Hence due to prolong standing posture and, continuous working hours and absence of relaxing of body they suffered with arthritis problem, lower and upper back problem, headache, swelling on ankles, stiffness in leg and hand joints, numbness in body, reduced grip strength, limiting movement of fingers etc. Besides this there was a problem of slips, falls, repetitive body motion, and adoption of awkward posture for performing especially preparation and dishwashing activities besides cooking activity. Mainly lower back and leg/feet were the affected body parts while doing the work.

5. Final report on the Study of Work-related Musculoskeletal Disorders in Catering Industry in Hong Kong (2011) by Occupational Safety \& Health Council depicts that the top three prevalence of WMSDs in catering industry in Hong Kong were $71.7 \%, 69.6 \%$ and $68.8 \%$ among the workers who work as senior chef, dimsun chef and BBQ chef in Chinese restaurant respectively. People who work in the kitchen have higher pain level when compared with those who work in floor and other sectors. Consistently, the most affecting body part was shoulder. (http://www.oshc.org.hk/oshc_data/files/OSHInfo rmation/Musculoskeletal\%20Disorders_Catering_ Eng.pdf)

6. Oxenburgh (1991) observed the involvement of both arms during meat processing; one arm and wrist required to adopt a static posture to hold the meat steady, while the other arm was used to cut meat with the wrist in ulnar deviation and out of its strongest midline position.

7. Van der Doelen \& Barsky (1990) observed that the force applied by a worker to cut meat depended on the position the wrist takes with respect to the arm, the distance from the wrist to the point of force application, the sharpness of the knife being used and the toughness of the product being used. A blunt knife or tough or semi-frozen meat will increase the force required to cut meat.

8. Yesmin, K., (2013), identified the prevalence of WRMDs among the restaurant workers. The study design was cross-sectional. Total 100 samples were selected conveniently for this study from a restaurant The Westin Dhaka. the researcher found $78 \%$ of the participants had musculoskeletal disorders with higher prevalence of pain. The result indicates that most discomfort of the body regions is in the neck (22\%), spine (38\%) and knee $(24 \%)$. Most common symptom of WRMDs was pain $(82 \%)$ and the most affected body part was spine $(38 \%)$. The maximum severity of symptom was moderate $(57.7 \%)$. The most common risk factors were working in same position for (38\%) and carry heavy load for $(35 \%)$ participants.

9. Work-related Musculoskeletal Disorders (WMSDs) in the restaurant workers have increased significantly over recent years (Guo et al., 2004). Among 905 restaurant workers, 785 (84\%) reported experience of WMSD in the previous month, WMSD in the previous month, with a high prevalence of shoulder $(58 \%)$, neck (54\%), lower back/waist (53\%) and finger/waist (46.5\%) disorders, among hotel restaurant workers in Taiwan (Chyuan et al., 2004).

\section{Methodology:}

Total 60 respondents (12 hotels) were purposively selected for the present study from the Vadodara, Anand and Ahmedabad cities, Gujarat state. It was conducted in one phase only i.e. field survey followed by interview sessions and observations. The respondents were required to conduct their working cycle as usual and different postures were observed during work and were recorded. The pictures and videos were not taken as it was not permitted by any of the management. The repetitive and awkward postures were observed more. Investigator used the snowball sampling technique due to the time limitation. Those respondents working since last two years in the same property were selected for the present study. Both male and female were included in this study.

\section{RESULTS AND DISCUSSIONS:}

From the interviews and observations, it was shown clearly that the subjects were exposed to the awkward postures during long working hours. Result shows that the 'gender' of the respondents was cent percent 'male'. The mean age of the respondents working in kitchen found to be $(n=60)$ was 30.5 years. Education qualification of the 55 percent respondents was upto higher education. Current job experience of the respondents was found between 2-4 years i.e. $77 \%$ of the respondents. The current paper does not consist of 
actual pictures of the respondents as permission was not given for the same.

While performing activities the respondents adopted bending - cum- repetitive posture, with back, and hand flexion. Standing -cum-stretching posture was adopted. Palmer (2007) claimed that repetitive work, static loading are responsible for most of the WRMSDs. Musculoskeletal disorders were characterized on the basis of frequently incurred injuries. The results showed that the incidence was more in the calf muscle (26\%), lower back (23\%) and wrist $(21 \%)$. However, most food production staff indicated pain in more than one body region.

\section{CONCLUSION:}

This paper has presented the approach to find out the occupational risk of the workers at the selected hotels of food production staff. From the findings, the workers were exposed to the awkward posture which leads to the WRMSDs. In order to reduce musculoskeletal problems, correct postural practices, proper design of tools and equipment significant can prevent MSDS.

\section{RECOMMENDATIONS:}

A recommendation evolves out of the context in which the study was conducted. The purpose of the study was to record different postures adopted by the food production staff at work and to estimate the work related musculoskeletal disorders among workers. Though, the study had some limitations but some further step that might help for the better accomplishment of further research. For the ensuring of the generalization of the research it is recommended to investigate a large sample. But due to time limitation there was not able to gather huge amount of participants and for this result cannot be generalized.

\section{REFERENCES:}

1. Chyuan, J., Du, C., Yeh, W., and Li, C., (2004). Musculoskeletal disorders in hotel restaurant workers. Occupational Medicine, 54: 55-57. Cited From, Khaleda. Y., Bachlor of Science of Physiotherapy Session 2007 - 2008, "Prevelence of common work related Musculoskeletal Disorders among the restaurant

2. Fazi, H., et. Al (2017) Ergonomics study for workers at food production industry, Faculty
Mechanical Engineering, University Malaysia Pahang, 26600 Pekan, Pah

3. Guo, H., Chang, Y., Yeh, W., Chen, C., and Guo, Y., (2004). Prevalence of musculoskeletal disorder among workwers in Taiwan : A nation Wide study. Journal of occupational Health, 46; 26 -36. Cited From, Khaleda. Y., Bachlor of Science of Physiotherapy Session 2007 - 2008, "Prevelence of common work related Musculoskeletal Disorders among the restaurant workers".

4. Jafry $\mathrm{T}, \mathrm{O}$ Neill $\mathrm{DH}$. The application of ergonomics inrural development: A review, Appl Ergon 2000 - 31 : 263 - 268, Cited From Mohammadi. G., Industial Engineering department collage of engineering, Qom Universty of Musculoskeletal symtoms risk factor among workers in Rubber industry.

5. Khare. T., Research scholar, College of Home Science, Govind Ballabh Pant University of agriculture and technology Pantnagar, Udham Singh nagar. Uttarakhand, "Work Assessment of small scale Restaurant workers and their enterprising ability, june 2014.

6. Linton, S.J. and Kanwendo, K., (1989). Risk Factors inn the psychosocial work environment for nek and shoulder pain in secredaies. Jornal of occupational Medicine, 31(7) : 609 - 13, Cited From , Khaleda. Y., Bachlor of Science of Physiotherapy Session 2007 - 2008, "Prevelence of common work related Musculoskeletal Disorders among the restaurant workers".

7. Oxenburgh, M. (1991). Case 45 - Reduction of musculoskeletal hand injuries in meat processing. In Increasing productivity and profit through health and safety (pp. 239- 242). North Ryde, NSW: $\quad \mathrm{CCH}$ International. Investigating musculoskeletal disorders in New Zealand meat processing using an industry-level participative ergonomics approach (PDF Download Available). Available from: https://www.researchgate.net/publication/2632772 36_Investigating_musculoskeletal_disorders_in_N ew_Zealand_meat_processing_using_an_industrylevel_participative_ergonomics_approach [accessed Sep 26, 2017].

8. Sanon, V. (2014). Agency - Hied hotel Housekeepers. An at risk Group for Adverse Health outcomes. Workplace Health saf., 62 (2) : 86. Cited From mehra. N. and Sharma. P. "To study the health problems of workers in hospitality industry in selected units of 
Uttarakhand ", Asian journal off Home Science, December 2015 , 353 - 359 .

9. van der Doelen, J. A., \& Barsky, S. J. (1990). Repetitive strain injury within the meat-processing industry. Occupational Health in Ontario, 11(4), 154 - 167. Investigating musculoskeletal disorders in New Zealand meat processing using an industry-level participative ergonomics approach (PDF Download Available). Available from: https://www.researchgate.net/publication/2632772 36_Investigating_musculoskeletal_disorders_in_N ew_Zealand_meat_processing_using_an_industry level_participative_ergonomics_approach [accessed Sep 26, 2017].

10. Yesmain K. (2013), " Prevalence of common work related musculoskeletal disorders among restaurant workers", Unpublished thesis, Bangladesh Health Professions Institute , Department of Physiotherapy, Bangladesh 